\title{
FREUD E DARWIN: A INFLUÊNCIA DO EVOLUCIONISTA INGLÊS SOBRE O PAI DA PSICANÁLISE E A DEMARCAÇÃO DE UM LUGAR
}

\section{ARTIGO ORIGINAL}

NASCIMENTO, Rodrigo Barbosa ${ }^{1}$

NASCIMENTO, Rodrigo Barbosa. Freud e Darwin: A influência do evolucionista inglês sobre o pai da psicanálise e a demarcação de um lugar. Revista Científica Multidisciplinar Núcleo do Conhecimento. Ano 05, Ed. 09, Vol. 06, pp. 107-130. Setembro de 2020. ISSN: 2448-0959, Link de acesso: https://www.nucleodoconhecimento.com.br/psicologia/freud-e-darwin

\section{RESUMO}

A influência de Charles Darwin sobre os escritos de Sigmund Freud por muito tempo foi um assunto quase nada discutido, principalmente quando o nome do pai da psicanálise esteve associado às teses evolucionistas de Lamarck. Contudo, graças a Lucille Ritvo, o entendimento sobre a presença de Darwin na obra de Freud se tornou diferente, sobretudo a partir da publicação de seu livro A influência de Darwin sobre Freud: Um conto de duas ciências. Meticulosamente, Ritvo tornou possível compreender, não apenas a curiosa admiração de Freud por Darwin e a grande influência do evolucionista sobre seus escritos, mas também o estatuto filogenético nos textos de Freud da maneira como realmente foi postulado. No entanto, embora a importância da contribuição de Ritvo para a psicanálise seja imensa desde seu campo teórico, a autora ainda é pouco consultada ou até mesmo esquecida. Sendo assim, o objetivo desse estudo é demonstrar a influência de Darwin sobre Freud a partir das contribuições de Ritvo, e também, como pano de fundo, promover uma tentativa de tornar a autora menos esquecida, que, por sua vez, justifica a significância e o desenvolvimento desse estudo ao dar foco e concedê-la os devidos créditos dentro de toda essa linha de discussão. No intuito de alcançar o objetivo proposto, foram

\footnotetext{
${ }^{1}$ Graduando em Psicologia pela Universidade Salvador.
} 
utilizados todos os artigos da autora publicados na literatura cientifica, assim como sua dissertação e seu livro. Além disso, também foram utilizadas as obras de Freud e alguns artigos e livros sobre temática em questão objetivando dar maior solidez ao estudo. Por fim, conclui-se que as contribuições de Ritvo são fundamentais na discussão a respeito da influência de Darwin sobre Freud, pois, além de demonstrar como realmente o evolucionista influenciou o psicanalista, ela ofereceu um percurso de entendimento teórico próprio e uma melhor descrição histórica da formação de Freud enquanto cientista, em especial ao atentar-se para a grande influência do professor Carl Claus na aproximação de Freud com Darwin e os estudos históricoevolutivos. Ademais, algumas considerações da autora junto a tradução de seu livro, por vez, sofrem da falta de atualização de alguns conceitos/termos devido a época de sua publicação.

Palavras-chave: Charles Darwin, evolucionismo, Lucille Ritvo, psicanálise, Sigmund Freud.

\section{CONSIDERAÇÕES INICIAIS}

O espectro de Darwin é evidentemente axiomático. Essa expressão advoga a veridicidade da influência de Darwin sobre a própria biologia, sobretudo a partir da publicação de seu maravilhoso livro A Origem das Espécies (1859), no qual apresentou sua teoria da evolução das espécies por meio da seleção natural e modificou a maneira como os animais e os seres humanos eram compreendidos, tornando-se uma representação de "uma verdadeira revolução cientifica de primeira ordem" (BUICAN, 1990, p. 46), e, num momento posterior, também influenciou mais acentuadamente com a publicação de A Origem do Homem e a Seleção Sexual (1871). No entanto, essa expressão também se caracteriza como uma boa maneira de representar os limites transcendidos por sua teoria. Em outras palavras, a sua demasiada influência sobre os outros saberes.[2]

É correto afirmar que um homem como Darwin possuía muito mais conhecimento do acreditava ter; assim sendo, não é de se espantar que "as consequências de seu conhecimento cheguem tão longe em diferentes direções" (LORENZ, 2009, p. 9). A 
influência do evolucionista inglês transitou desde o campo da agricultura e da medicina até o da psicologia (ROSE, 2000). Especificamente sobre a última, de maneira direta, contribuiu para a emergência do movimento funcionalista inglês, assim como para o crescente interesse na psicologia comparada e no estudo sistemático das diferenças individuais (GOODWIN, 2005).

Há, no entanto, outras importantes contribuições de Darwin. Ele impactou demasiadamente em grandes autores como Skinner e Freud. Especialmente acerca do segundo, pode-se dizer que "Freud, por sua vez, talvez tenha sido influenciado por Darwin em um grau muito maior do que aquele que é, em geral, reconhecido" (SIMANKE, 2009, p. 233-234). Em outras palavras, Darwin consistiu em uma figura que transcendeu o campo estrito de produção teórica e desdobrou-se nas raízes da formação cientifica e pessoal do pai da psicanálise (RITVO, 1992).

Apesar disso, a compreensão dessa relação foi, outrora, inevitavelmente nebulosa, particularmente no tempo que antecedeu as contribuições da autora Lucille Ritvo.

Lucille B. Ritvo, nascida em 11 de julho de 1920 em Middle Village, foi e é grande destaque no assunto "Darwin-Freud", especialmente após a publicação de seu livro oriundo de sua tese de doutorado, A influência de Darwin sobre Freud: Um conto de duas ciências, em 1990. Anteriormente à publicação de seu livro, a autora já havia demonstrado seu interesse sobre a temática em suas publicações cientificas (1965; 1972; 1974), assim como em sua dissertação Darwin of the Mind (1963). Aproximadamente 2 anos após a publicação de seu livro, as traduções do mesmo percorriam o mundo, sendo publicada no território brasileiro em 1992.

É certo que, antes de Ritvo, a maneira como se interpretavam as ideias filogenéticas de Freud eram minimamente equivocadas ou certamente negligenciadas e deixadas de lado. Portanto, os discursos acerca dos desfechos da biologia evolutiva de Darwin sobre os escritos psicanalíticos de Freud de forma alguma eram sólidos. Dito isso, "pode-se afirmar com grande embasamento, ao menos desde os estudos já clássicos e de grande repercussão de Ritvo [...] que a presença de Charles Darwin (1809-1882) 
na vida e na obra de Sigmund Freud (1856-1939) é extraordinária" (FERRETI, 2011, p. 110).

Embora alguns autores como o Assoun (1983) e o Ferreti (2011), e até mesmo a própria Ritvo (1992), já tenham de certa maneira demonstrado o contrário, outrora os postulados de Freud estiveram comumente ou totalmente associados ao nome de Lamarck e pouco ao nome de Darwin (YOUNG, 2006). De acordo com Bowlby (1977, p. 63), "Freud era sem dúvida um evolucionista. Mas nada indica que fosse um darwinista". A afirmação de Bowlby é certamente precedida e parte da percepção de Ernest Jones sobre o evolucionismo de Freud, no qual afirma que apesar de todas as evidências científicas que contrariavam as teses evolucionistas - como o caso da herança dos caracteres adquiridos - de Lamarck, principalmente "desde o tempo de Darwin" (JONES, 1953, p. 311), "Freud permaneceu, do começo ao fim de sua vida, o que se deve chamar de obstinado adepto desse lamarckismo desacreditado" (JONES, 1953, p. 311).

Contudo, segundo Ritvo (1992, pp. 75-76), com exceção de um texto publicado em 1783 acerca da cocaína, "não há referências a Lamarck em quaisquer dos textos científicos de Freud e em nenhuma referência em suas publicações psicanalíticas", pelo menos não de maneira direta. Além disso, mesmo quando Freud leu a Philosophie Zoologique (1809) de Lamarck, "não há evidência de que tenha extraído alguma coisa utilizável de sua [...] exploração de Lamarck” (RITVO, 1992, p. 83). Em contrapartida, no que se refere a Darwin, além das mais de vinte referências a este em seu texto (RITVO, 1963), muitas vezes também utilizou um "modo de pensar sobriamente darwiniano" (FREUD, [1920]2010, p. 229).

É na linha de objeção às considerações empregadas por alguns (JONES, 1953; BOWLBY, 1973) e outros[3], que Ritvo surge como uma das principais ou até mesmo a principal autora acerca da discussão sobre a relação entre Darwin-Freud e o estatuto filogenético em Freud, em especial por enfatizar a grande presença de Darwin nos escritos de Freud, também denunciando certos equívocos ao longo da elaboração dessa discussão e ter realizado uma profícua consulta sobre a vida do psicanalista "acusando a posse de várias obras de Darwin" (FERRETI, 2011, p. 110) e, 
principalmente, revelando "uma funda inserção, sobretudo durante sua formação acadêmica, na biologia darwinista" (FERRETI, 2011, p. 110).

Sendo assim, pode-se dizer que as contribuições de Lucille Ritvo são de tamanha importância para qualquer um que queira ampliar os horizontes da discussão sobre a filogenia e Darwin nos textos freudianos e até mesmo para todos aqueles que almejam se tornar psicanalistas, sendo o último pressuposto sustentado nas afirmações do próprio Freud acerca da importância da biologia evolutiva na formação do psicanalista.

"O conteúdo programático para o analista [...] precisa abarcar o conteúdo das Ciências Humanas, conteúdo psicológico-cultural e sociológico quanto o anatômico biológico e histórico-evolutivo" (FREUD, [1927]2019, pp. 292-293).

Em vista disso, o âmago desse trabalho visa demonstrar a relação de Darwin e Freud embasado exclusivamente nos trabalhos publicados por Ritvo e nas referências do próprio Freud, muito embora seja mencionado outros autores suscintamente [4]. Além disso, também se propõe a trazer o impacto de Ritvo sobre o estatuto filogenético na obra de Freud e, principalmente demarcar definitivamente o lugar da autora nessa discussão. Por motivos de entendimento, a exposição desse estudo será dividida em dois momentos: o primeiro atendo-se a questões gerais - históricas e pessoais - no qual será abordado desde a formação acadêmica e cientifica de Freud, em especial o seu período de formação médica e os momentos que a antecedem; e o segundo a questões estritamente teóricas, como por exemplo aquelas encontradas em Totem e Tabu (1913), por vez consideradas um "devaneio darwiniano sobre a origem da humanidade" (ROUDINESCO, 1998, p. 757).

\section{DARWIN E FREUD: QUESTÕES GERAIS}

É evidente que a maneira como Freud se relacionava com Darwin transcendia o parâmetro estritamente teórico. O célebre evolucionista possuiu um papel fundamental na consolidação do pai da psicanálise enquanto cientista. Para Freud, Darwin não era apenas um biólogo como qualquer outro que desenvolveu uma teoria que ele gostaria de utilizar; era muito mais que isso, era o "Grande Darwin" (FREUD, 
[1901]2006). Nessa mesma linha de pensamento, nota-se que a influência e admiração era tanta, que, além de se posicionar na mesma estante dos golpes a integridade do eu, em todo seu escopo teórico referiu-se a Darwin mais de vinte vezes de maneira extremamente positiva, desde o Estudo sobre a Histeria (1895) até Moises e o Monoteísmo (1939), não se restringindo apenas ao livro mais famoso de Darwin: A Origem das espécies (1859) e utilizando de outros livros não tão convencionais do evolucionista, como: A variação de animais e plantas sob domesticação (1868), A Descendência do Homem e a Seleção sexual (1871) e A Expressão das emoções no homem e nos animais (1872) (RITVO, 1963; 1965; 1974; 1992).

A vida de Darwin e Freud coincidiram por aproximadamente mais de um quarto do século, até a morte do célebre evolucionista em 1882, um ano depois da formatura de Freud em medicina. Contudo, ainda adolescente, no período anterior à sua entrada na faculdade de medicina (1865-1873), a presença de Darwin já era existente mesmo que de maneira aparentemente latente. Em um trecho de seu Estudo Autobiográfico (1925), Freud discorre acerca de seu período antes da escola de medicina mencionando que:

Sob forte influência da amizade formada com um colega, um tanto mais velho, que depois se tornou um político, quis estudar direito como ele, e desenvolver atividade pública. No entanto, eu era enormemente atraído pela teoria de Darwin, então em voga, pois ela prometia um extraordinário avanço na compreensão do mundo, e sei que a apresentação do belo ensaio de Goethe sobre a natureza, numa das populares conferências do Prof. Carl Brühl, pouco antes de eu concluir o curso, fez com que eu decidisse me matricular em medicina. (FREUD, [1925]2011c, p. 78).

Além disso, essa época da vida de Freud coincidiu com a popularização das ideias darwinianas (RITVO, 1974) e, consequentemente, do biólogo e filósofo alemão Ernest Haeckel[5], um dos principais apoiantes de Darwin. Coincidiu também com o sucesso das traduções da quarta edição de A origem das espécies (1859) e A variação de plantas e animais domesticadas (1869) realizadas pelo zoólogo e entomólogo Victor Carus[6] após o desastre das primeiras traduções dos livros de Darwin feitas pelo zoólogo e paleontólogo Heinrich Georg (RITVO, 1992). 
Todavia, atendo-se a Haeckel, além de apoiador, este era um defensor e divulgador das ideias de Darwin. Haeckel é responsável por levar a teoria de Darwin através dos muros fechados da Alemanha da época. É certo que as primeiras divulgações da teoria darwiniana sofreram uma repulsa pela comunidade científica e Haeckel merece os devidos méritos por se posicionar a favor publicamente, visto que tal feito e a aproximação com este conhecimento poderia até mesmo ser considerado penoso para alguns da época (RITVO, 1992).

Felizmente, em 1865 a repulsa da academia alemã começa a sofrer alterações significantes. As discussões sobre as teorias de Darwin passam a tomar conta dos muros fechados da Alemanha, em especial devido ao árduo trabalho de Haeckel, feito que acabou por resultar na declaração de Thomas Henry Huxley[7] — braço direito de Darwin - sobre o mesmo, no qual dizia ser Haeckel "um dos mais capacitados dos jovens zoólogos da Alemanha", bem como o "corifeu do movimento darwiniano na Alemanha" (HUXLEY, 1901, p. 287 apud RITVO, 1992, p. 29)[8]. Em outras palavras, uma das figuras mais importantes acerca dos debates evolucionistas; não obstante, para Haeckel, o ônus de seu apoio a Darwin foi a concentração de toda a resistência, todo ódio e raiva por parte dos opositores, ação que isentou o próprio Darwin disto (RITVO, 1992).

Este desempenha um papel curioso de duplo e de propagandista da filosofia darwinista. Desdenhando a prudência de seu mestre inglês, ele erige a teoria de Darwin em darwinismo, ele mesmo reconstruído numa doutrina dependendo da Ciência, da filosofia e da visão do mundo, que batiza de "Monismo": em Haeckel, encontramos o primeiro "darwinista", pretendendo ser mais darwiniano que o pr6prio Darwin! (ASSOUN, 1983, p. 217-218).

Igualmente, Lorenz (2009, p. 8) menciona que "os biólogos modernos são muito mais 'darwinistas' do que Darwin".

Evidentemente, o papel de Haeckel foi essencial para que Freud tivesse seus primeiros contatos com a teoria de Darwin. Se não fosse ele, talvez os muros da Alemanha ainda estivessem fechados para a teoria e, pior que isso, talvez os ouvidos deixassem de escutar as ondas de verdade que ali ecoavam para Viena e os olhos 
deixassem de enxergar o feijão que aos poucos germinava em um solo aparentemente fértil.

Haeckel não foi simplesmente um dos que mais difundiram 0 darwinismo, mas consumou o casamento da teoria de Darwin com a ciência e com a epistemologia de seu tempo. Correlativamente, ele contribuiu mais do que ninguém para o uso de Darwin como referente histórico e ideológico. Finalmente, é nele que encontramos definido e codificado o uso da sequência Copérnico-darwiniana de que Freud, entre outros, se tornará o usuário (ASSOUN, 1983 p. 218).

Após esse período, ao entrar na faculdade de medicina aos 17 anos, Freud teve contato com três professores que tiveram um papel central na sua formação acadêmica, são eles: Brücke, Carl Claus e Meynert. Contudo, apenas os dois últimos tiveram, de fato, uma maior influência nas questões darwinianas de Freud, pois supõese que tal conhecimento não havia tanto acréscimo nos estudos de Brücke, principalmente porque este também partilhava de algumas críticas realizadas por Meynert acerca da acepção de Darwin sobre os instintos (RITVO, 1992). Dito isso, pode-se afirmar que o segundo, Carl Claus, é o mais importante na formação evolucionista de Freud.

Carl Friedrich Claus (1835-1899), zoólogo alemão, também conhecido por ser um opositor das ideias de Haeckel, foi professor da Universidade de Viena e fez parte do departamento de zoologia da instituição. Coincidentemente chegou à universidade de Viena no mesmo período em que Freud se inscreveu na universidade, com intuito de modernizar e melhorar o departamento de zoologia da instituição (GAY, 2012)

Claus foi um dos adeptos da teoria darwiniana na obscura Alemanha da época[9]. Contudo, a maneira como ele se relacionava com a teoria era um tanto diferente. Para o mesmo, era necessário que houvesse uma demasiada cautela, principalmente em determinadas afirmações que possuíam um maior peso científico que, por sua vez, é característica fundamental de toda a teoria de Darwin. A cautela de Claus, apesar de parecer sensata para alguns, para outros foi motivo de raiva. É certo que a partir disso, não apenas no campo teórico, mas também no campo pessoal, grandes embates 
entre ele e Haeckel surgiram, mesmo que de alguma forma suas ideias convergissem no que se refere à aceitação de parte da teoria de Darwin (RITVO, 1992).

Embora houvesse essas pequenas questões associadas ao nome de Claus, ele foi bastante importante na aproximação de Freud com o pensamento darwiniano, principalmente porque, no período de formação do pai da psicanálise, Claus desenvolveu um curso chamado "Biologia e Darwinismo", do qual Freud participou (RITVO, 1963; 1972).

Ao contrário do que foi assumido pelas pesquisas ontogenéticas e filogenéticas de Freud no laboratório de Brücke, não foi Brücke, mas Claus, de quem Freud obteve sua orientação evolutiva na ciência. Há uma consistência impressionante nas visões mantidas por Darwin, Claus e Freud sobre os aspectos da teoria de Darwin que eram controversos na época ou posteriormente se tornaram (RITVO, 1974, p. 181, grifo nosso e tradução nossa).

No entanto, sem motivos explícitos, Freud não menciona Claus ou confere os devidos méritos a ele sobre os seus conhecimentos evolucionistas. De acordo com Gay (2012) independente das razoes de Freud, suas referências aos trabalhos realizados com Claus mostram um demasiado descontentamento consigo próprio, assim como com os outros. Logo, "é notável que Freud não tenha encontrado lugar para o nome de Claus em seus escritos autobiográficos" (GAY, 2012, p. 49).

Além disso, de modo convergente, segundo Ritvo (1992), os motivos podem ter sido de raiz pessoal, visto que Freud confere a Brücke - que possuía um comportamento paternal - muito de seus avanços científicos. Logo, acaba por oferecer um contraste radical (GAY, 2012).

Desta maneira, supõe-se que o resultado final disso pode ser encontrado na pouca atenção dada por parte daqueles que se debruçaram em construir as biografias de Freud, seja por negligência ou por simples crença de que devido à não menção de Freud, este não era importante.

No seu período de estudos com Theodor Hermann Meynert, célebre anatomista, Freud se aproximou de algumas noções de Darwin utilizadas em Expressões das 
Emoções (1872) - o que enfatiza suas interlocuções com noções naturalistas e filogenéticas - aplicando-as a ideias acerca da histeria. Essas noções darwinianas, antes mesmo de Freud, foram incorporadas por Meynert em sua obra Psychiatrie (1884), mesmo com sua discordância quanto a alguns pontos, como por exemplo as noções de instinto apresentadas por Darwin (RITVO, 1963; 1992)

Não obstante, o papel de Meynert teve como resultado não apenas o uso das ideias de Darwin em uma das principais obras de Freud, o Estudo sobre a Histeria (1985) mesmo que seja onde tal conhecimento aparece com maior ênfase -, mas também no uso de Freud em seus estudos sobre o Chistes, em especial acerca da fisiológica do riso[10].

Em suma, é evidente a forma como Darwin e seus apoiadores influenciaram todo o desenvolvimento de Freud desde a construção e complementação de seu escopo teórico à sua formação enquanto cientista e seu desenvolvimento pessoal. Dito isso, visto que este possuía uma grande admiração por Darwin, não é de se espantar que tenha posicionado suas contribuições na mesma estante que Copérnico e o incrível evolucionista, formando, então, os três maiores golpes ao narcisismo humano.

No decorrer dos tempos, a humanidade teve de tolerar dois grandes insultos a seu ingênuo amor-próprio por parte da ciência. O Primeiro, quando descobriu que a nossa Terra não é o centro do universo, e sim, uma ínfima partícula de um sistema cósmico cuja grandeza mal se pode imaginar. Essa afronta se liga, para nós, ao nome de Copérnico [...]. $O$ segundo, quando a pesquisa biológica aniquilou a suposta prerrogativa humana na criação, remetendo a descendência dos homens ao reino animal e apontando o caráter indelével de sua natureza animalesca. Essa reavaliação ocorreu em nossos dias sob a influência de Darwin, Wallace e de seus predecessores [...]. O Terceiro e mais sensível insulto, no entanto, a mania de grande humana deve sofrer da pesquisa psicológica atual, que busca provar ao Eu que ele não é nem mesmo senhor de sua própria casa, mas tem de satisfazer-se com parcas notícias do que se passa inconscientemente na sua psique (FREUD, [1917]2014a, pp. 380-381). 


\section{DARWIN E FREUD: QUESTÕES ESTRITAMENTE TEÓRICAS}

A noção de conflito e adaptação, presentes primordialmente em A Origem das Espécies (1859) são axiais na teoria darwiniana. Ambos, de certo modo, fundamentam uma das principais colaborações autorais de Darwin: a seleção natural, que, por sua vez, caracteriza uma de suas distinções quanto ao evolucionismo de Lamarck pautado na ortogenética[11] e volição[12]. A primeira, a noção ortogenética da evolução, pressupõe um "desenvolvimento progressivo em direção à perfeição" (RITVO, 1992, p. 55), um "aperfeiçoamento ininterrupto" (FOUCAULT, 1992, p. 379). [13]

Lamarck só pensava as transformações das espécies a partir da continuidade ontológica que era a da história natural dos clássicos. Ele supunha uma gradação progressiva, um aperfeiçoamento ininterrupto, uma grande superfície dos seres que podiam formar-se uns a partir dos outros (FOUCAULT, 1999, p. 379).

Já a segunda, a noção de volição ou vontade, grosso modo, é designada por Lamarck como "a vontade do próprio ser vivo em se modificar" (BIZZO, 1987, p. 42).

Em contraste, o evolucionismo de Darwin enfatiza o conflito, a "luta pela existência" (DARWIN, 1876, pp. 48-61), e é no cerne da teoria psicanalítica de Freud que encontramos soterrados ossos primitivos prontos para serem descobertos. As duas noções presentes na teoria de Darwin não só estão presentes no escopo teórico da psicanálise freudiana, mas são princípios onipresentes em toda a sua totalidade, seja de forma manifesta ou latente.

A ideia de conflito é onipresente no trabalho de Freud e permaneceu básica para seu pensamento em toda sua vida. Freud considerava não apenas que os sintomas neuróticos são baseados em conflitos patogênicos, mas também os conflitos são o núcleo essencial da personalidade humana normal (RITVO, 1992, p. 85).

A presença da ideia do conflito na obra de Freud pode ser visualizada de algumas formas. A primeira delas consta em seu Estudo sobre a Histeria (1895), no qual a origem dos sintomas histéricos é oriunda e/ou resultado do conflito entre um desejo - ou pensamento inaceitável - e a consciência, melhor dizendo, entre o inconsciente e o consciente. A segunda é perceptível nas afirmações de Freud acerca das forças 
pulsionais. Em resumo, para Freud, o conflito existia entre o consciente e o inconsciente, entre as forças pulsionais e o ego - a última, após a transição para a segunda topologia. Por fim, após a teoria estrutural do ego, id e o super ego (FREUD, [1923]2011b) - momento popularmente conhecido como segunda tópica ou segunda topologia - , o ego torna-se, enquanto função, um órgão adaptativo[14] cujo encargo seria mediar ou evitar os conflitos, seja intrapsiquicamente - entre duas ou mais dessas estruturas - , assim como alguma dessas estruturas e o mundo externo (RITVO, 1992).

Ademais, há um adendo pertinente acerca da noção do conflito. Pode-se dizer que até as contribuições de Ritvo e algumas observações de outros autores, de forma alguma essa noção foi atribuída a Darwin. Provavelmente, foi direcionada a autores como Carl Ludwig, Ernest Brücke e Du-Bois Reymond, que, por sinal, também partilhavam dessa perspectiva (RITVO, 1992).

Uma outra noção fundamental - apesar de controversa - é a de recapitulação. Esta aparece de maneira recorrente na obra de Freud, particularmente descrita a partir perspectiva que a ontogenia repete a filogenia. Esta foi utilizada no desenvolvimento das teorias psicossexuais de Freud, assim como em seu texto Totem e Tabu (FREUD, [1913]2012a). No primeiro caso, as fases psicossexuais — até o período fálico seriam, de algum modo, uma recapitulação do período arcaico de forma sintetizada, como apontava as teorias embriológicas - ao ressaltar que os períodos primitivos do desenvolvimento dos animais eram uma recapitulação da história da espécie — outrora utilizadas por biólogos adeptos da recapitulação (RITVO, 1963; 1992). No segundo caso, tenderia a uma constatação filogenética das teses do complexo de Édipo, no qual entram em concordância com a horda primal de Darwin.

Freud aplicou a consequente teoria da recapitulação —reestabelecida por Darwin - em totem em Tabu, a paralelismo que ele via na mitologia, em material etnológico, e no complexo de édipo. Pôde assim, reconstruir o que considerava a "verdadeira" morte do pai pela "horda primal de Darwin" e a consequente culpa e repressão do incesto. Freud depois aplicou a ideia do paralelismo ou recapitulação em Psicologia dos Grupos e a Análise do Ego (1921) para transpor o hiato entre psicologia individual e de grupo e em Moises e o Monoteísmo para reconstruir a 
origem não apenas da religião judaica, mas da crença no monoteísmo e de sua aceitação pelo homem (RITVO, 1992, p. 180, grifo do autor).

Em seu livro A Descendência do Homem e a Seleção Sexual (1871), Darwin constrói algumas hipóteses que seriam utilizadas por Freud, que resultariam na noção da horda primal tão axial em seus textos, especialmente em Totem e Tabu (1913). A seleção sexual, um dos princípios que Darwin afirmou agir em conjunto com a seleção natural, alegava a vantagem que certos indivíduos possuíam sobre outros do mesmo sexo e espécie, porém direcionadas exclusivamente à noção de reprodução. Nesses estudos, Darwin percebeu a importância desse outro mecanismo no processo evolutivo; diz ele:

Há muitas outras estruturas e instintos que devem ter sido desenvolvidos através da seleção sexual, tais como as armas de ataque e meios de defesa dos quais os machos são dotados com a finalidade de lutar e afugentar seus rivais, sua coragem, combatividade, os seus diversificados ornamentos, os órgãos que os capacitam a cantar e produzir diversos sons, e as glândulas para emitir odores [...] É evidente que tais características resultam da seleção sexual, e não da seleção natural, uma vez que os machos desprovidos de armas, ornamentos ou atrativos poderiam ser igualmente bem sucedidos na batalha pela vida, ou no que se refere a reprodução, desde que não tivessem de competir com seus rivais bem dotado (DARWIN, [1871]2019, p. 170).[15]

Seguido disso, segundo Darwin ([1871]2019), em algumas espécies, os machos tendem a ter mais de uma fêmea, assim como, muitas vezes, a disputa pelas fêmeas configura-se como a razão de inúmeros conflitos em determinados povos. Em uma linha de pensamento evidentemente parecida, ao conjecturar sobre a ideia da horda primal, sobretudo no desenvolvimento teórico posto em Totem e Tabu (1913) e suscintamente repetido em Moisés e o Monoteísmo (1939), Freud menciona que "nos tempos primordiais o homem primitivo vivia em pequenas hordas, cada um sob o domínio de um macho forte" (FREUD, [1939]2018, p. 114). Posto isso, o macho alfa da horda era certamente o dono de tudo, era "o pai de toda a horda" (FREUD, [1939]2018, p. 115), domínio exercido, principalmente através da violência (FREUD, [1939]2018). Logo, todas as fêmeas eram de sua propriedade, sejam elas de sua própria horda ou roubadas de outras hordas (FREUD, [1939]2018). Dito isso, 
evidentemente qualquer outro macho que tentasse se apoderar das fêmeas do pai ciumento "eram abatidos, castrados ou banidos" (FREUD, [1939]2018, p. 115).

Todavia, Freud designou que a estrutura desse sistema liderado por um macho alfa desdobra-se em uma rebelião por partes dos filhos, no qual estes se unem contra o pai com o intuito de dominá-lo e devorá-lo (FREUD, [1913]2012a).

O passo seguinte e decisivo para mudar esse primeiro tipo de organização "social" deve ter sido que os irmãos expulsos, que viviam em comunidade, se reuniram para subjugar o pai e devorá-lo cru, conforme o costume daqueles tempos. Esse canibalismo não deve nos chocar, ele prosseguiu longamente em épocas posteriores. $O$ essencial é que atribuímos a esses homens primevos as mesmas atitudes emocionais que podemos verificar nos primitivos da atualidade nossas crianças - mediante a pesquisa psicanalítica. Ou seja, que não apenas odiavam e temiam o pai, mas também o adoravam como modelo, e cada um deles queria, na realidade, tomar o seu lugar. $O$ ato canibal se torna compreensível, então, como tentativa de assegurar a identificação com ele pela incorporação de um pedaço dele (FREUD, [1939]2018, p. 115)

Por fim, a contribuição de Robertson Smith é o cerne da configuração da teoria psicanalítica utilizada por Freud, é como um desfecho perfeito. Este fornece a Freud a suposição de que a teoria da horda primal deu lugar ao clã totêmico constituído pelos irmãos (RITVO, 1992).

A Primeira forma de organização social surgiu com a renúncia institual, o reconhecimento de obrigações mútuas, o estabelecimento de instituições ditas invioláveis (sagradas), ou seja, os primórdios da moral e do direito. Cada indivíduo renunciou ao ideal de conquistar a posição do pai, à posse da mãe e das irmãs. Com isso, iniciou-se o tabu do incesto e o mandamento da exogamia [...] A recordação do pai prosseguiu nessa época de "aliança dos irmãos". Para substituto do pai foi encontrado um animal forte, que talvez fosse também temido inicialmente. Tal escolha pode nos parecer estranha, mas não havia, para os primitivos, o hiato que depois o ser humano estabeleceu entre si e os animais, e tampouco existe para nossas crianças, cujas fobias de animais pudemos explicar como medo do pai. Na relação com o animal totêmico se mantinha plenamente a original dicotomia (ambivalência) do laço afetivo com o pai. O totem era visto, por um lado, como ancestral de sangue e espírito protetor do clã, tinha de ser venerado e poupada; por outro lado, institui-se um dia de festa em que lhe davam o mesmo destino que tivera o pai primordial. Era abatido e devorado 
conjuntamente por todos os camaradas (a refeição totêmica, conforme Robertson Smith). Esse grande dia festivo era, na realidade, uma comemoração do triunfo sobre o pai obtido pelos filhos aliados (FREUD, [1939]2018, pp. 116-17, grifos do autor). [16]

Anos depois da construção da teoria da horda, esta foi mencionada a partir da associação com as noções de sugestão e hipnose, na qual a sugestão seria uma manifestação parcial do estado de hipnose, sendo ela firmemente baseada em uma predisposição que sobreviveu no inconsciente a partir da história evolutiva humana. Em acréscimo a essa proposição, ressaltam-se os procedimentos daquele que hipnotiza que, por vez, tendem a despertar no analisando uma porção de sua herança arcaica, que o torna dócil em relação ao pai, ao líder (RITVO, 1992). Portanto, tal feito retomaria a relação existente entre os membros da horda primal e o pai da horda.

Com suas medidas, o hipnotizador desperta no sujeito uma porção arcaica deste, a qual também se harmonizou com os pais e na relação com o pai experimentou uma revivescência individual, a ideia de uma personalidade muito potente e perigosa, ante a qual só se podia ter uma atitude passiva-masoquista, à qual a vontade tinha que se render, parecendo uma arriscada empresa estar a sós com ela, "cair-Ihe sob os olhos". Apenas assim, aproximadamente, nos é dado imaginar a relação de um indivíduo da horda primeva com o pai primordial (FREUD, [1921] 2011a, p. 91)

Além dessas, outras contribuições de Darwin à teoria psicanalítica de Freud também possuem seu valor. A própria ideia da história evolutiva e a discussão sobre o horror ao incesto, sobretudo acerca da possibilidade de ser algo inato. Sobre a primeira, como um bom darwinista, Freud atribuiu os passos de suas teorias e concepções à história evolutiva. Não apenas no caso da horda, mas também utilizou na compreensão da origem de sintomas e estados psicológicos. Melhor dizendo, é o seu costumeiro uso dos recursos filogenéticos ou, ao menos, sua tentativa de contribuir de alguma forma com essa discussão onde aloja sua grande inspiração pessoal — ou de tornar a psicanálise uma Naturwissenschaften.[17]

No que concerne à segunda, o horror ao incesto foi discutido por ambos os autores de maneira convergente em suas ideias - mesmo que não trocassem cartas e vivessem por tanto tempo a mesma época. A discussão a respeito da ideia de que a 
endogamia é prejudicial à espécie é primordialmente direcionada com a convergência entre Darwin e Freud, que compartilhavam com a discordância sobre a aversão ao incesto ser inata. A nível de reflexão, tudo indica que essa afirmação encontrada em Darwin fez Freud refletir e se perguntar algo como: Se a aversão não é inata, qual seria o momento na história evolutiva da espécie humana que ela poderia ter se originado?

De acordo com Ritvo (1992), Darwin propôs que em algum momento da nossa história primitiva, a formação de casais com parentesco distante tenha tido uma singela preferência, portanto, a comunidade, de algum modo, haveria se desenvolvido em cima desta configuração e, através da descendência dessas casais pautados nessa estrutura, seria possível supor que estes sobreviveriam mais que os outros e por isso se firmariam. A partir disto, pode-se dizer que esta analogia confere a capacidade de propor este olhar, o que torna provável que Freud tenha tido algo parecido.

Entretanto, Freud ([1913]2012a, pp. 17-41), no desenvolver de seus estudos, identifica como as primeiras produções de afetos são comumente incestuosas que, por sua vez, acaba por contrariar as teses que afirmavam a característica inata do horror ao incesto como premissa para esse contexto relacional.

Quinze anos depois, em Totem e tabu, contradisse todos os trabalhos antropológicos de sua época, mostrando que a proibição tinha como origem não o horror inspirado pelo incesto, mas o desejo que ele suscitava. Através dessa inversão essencial, que inscreveu a proibição no cerne da cultura e da relação do sujeito com a lei, Freud deu início ao debate sobre a universalidade do complexo de Édipo. Sua perspectiva era evolucionista e se apoiava na lenda darwinista da horda selvagem (ROUDINESCO, 1998, p. 373)

Sendo assim, embora ambos tenham se debruçado nesta questão, as conclusões sobre a endogamia e até mesmo a exogamia ainda são e foram demasiadamente obscuras, visto que ao longo de todo esse processo de entendimento, "ignoramos a origem do horror ao incesto", e agora, "nem mesmo podemos dizer onde procurá-la" (RITVO, 1992, p.143). Não obstante, Freud menciona resumidamente em Moisés e o Monoteísmo (1939) alguns direcionamentos acerca desta questão discutida em Totem e Tabu (1913), em especial, ao falar coisas como "Cada indivíduo renunciou ao ideal 
de conquistar a posição do pai, à posse da mãe e das irmãs. Com isso, iniciou-se o tabu do incesto e o mandamento da exogamia" (FREUD, [1939]2018, p. 116). Portanto, há de se considerar que de certa forma Freud exibiu uma tentativa de dar respostas a essas questões, mesmo que Ritvo apresente o contrário.

Em seu período de estudos com o professor Meynert, Freud obteve maior contato com as noções empregadas por Darwin em A Expressão das Emoções no Homem e nos Animais (1872), especificamente, os princípios gerais da expressão. Princípios estes empregados por Freud desde seu Estudo sobre a Histeria (1895) a outros textos como Chistes e sua relação com o Inconsciente (1905), especificamente, sobre a fisiologia do riso (RITVO, 1963; 1992).

Segundo Darwin ([1872]2009), existem três princípios que, como ressalta ele, são responsáveis por grande parte das expressões e gestos involuntários utilizados tanto por animais ditos inferiores quanto o homem, particularmente, sempre sob a influência de diversas emoções e sensações. São estes: o princípio do hábito associado útil; o princípio da antítese; e o princípio das ações devidas à constituição do sistema nervoso, totalmente independentes da vontade e, em um certo grau, do hábito.

Nas palavras de Darwin ([1872]2009, pp. 32-33):

O Hábito associado útil: Algumas ações complexas tem utilidade direta em certos estados de espirito para aliviar ou gratificar sensações, desejos etc; e toda vez que o mesmo estado de espirito é induzido, mesmo que pouco intenso, há uma tendência, pela força do hábito e associação, de os mesmos movimentos se repetirem, ainda que não tenham a menor utilidade. Algumas ações, normalmente associadas pelo hábito com certos estados de espírito, podem ser parcialmente reprimidas pela vontade, e nesses casos, os músculos que estão menos submetidos ao controle separado da vontade são os que mais tendem a agir, causando movimentos que reconhecemos como expressivos. Em alguns outros casos, a contenção de um movimento habitual requer outros pequenos movimentos que também são reconhecidos como expressivos

Antitese: Certos estados de espírito levam a algumas ações habituais que são úteis, tal como estabelecesse nosso primeiro princípio. Mas quando um estado de espírito oposto é induzido, há uma tendência forte e involuntária à realização de movimentos de natureza contrária, ainda 
que esses não tenham utilidade; e esses movimentos são, em alguns casos, fortemente expressivos.

Ações devidas à constituição do sistema nervoso, totalmente independentes da vontade e, em um certo grau, do hábito: Quando o sensório é intensamente estimulado, gera-se força nervosa em excesso. Esta é transmitida em certas direções, dependendo da conexão entre as células nervosas e parcialmente do hábito; ou fornecimento de força nervosa pode ser, aparentemente, interrompido. Os efeitos assim produzidos são por nós reconhecidos como expressivos. Esse terceiro princípio pode ser chamado, para efeito de síntese, de ação direta do sistema nervoso.

A afirmação de Freud que "todas as sensações e inervações pertencem a "expressões das emoções" que, como Darwin nos ensinou, consiste em ações originalmente cheias de sentido e adequadas a um fim" (BREUER e FREUD, [1895]2016, p. 260), confirma o já evidente uso de Freud das formulações teóricas de Darwin, entretanto, agora direcionado estritamente à obra de Darwin acerca das expressões.

Embora isso seja verdadeiro, de acordo com Ritvo (1992), de maneira explícita, Freud utilizou apenas dois desses princípios desenvolvidos por Darwin, o primeiro e o terceiro. Não obstante, a autora ressalta a possibilidade de Freud ter utilizado o princípio de antítese em alguns momentos, mas seria necessária uma maior investigação sobre a ideia de antítese na Alemanha[18] no período de vida de Freud.

No primeiro princípio, o caso de Fraü Cacelie[19] é o que melhor demonstra, quando Freud afirma o amplo uso de simbolização. A partir da leitura de Freud, Ritvo demonstra:

"Quando uma histérica", como sua paciente Frau Cacëllie, M., "cria uma expressão somática para uma ideia, emocionalmente matizada por simbolização", era de opinião de Freud que ela "depende menos do que se imagina de fatores pessoais ou voluntários. Ao tomar uma expressão verbal literalmente ao sentir o "golpe no coração" ou o "tapa no rosto" depois de alguma observação desatenciosa como um acontecimento real, a histérica não está tomando liberdades com as palavras, mas simplesmente revivendo mais uma vez as sensações a que a expressão verbal deve sua justificação. (RITVO, 1992, p. 232) 
Em suas conferências introdutórias (1916-1917), especificamente acerca da angústia, ao combinar com os conceitos de recapitulação, Freud menciona que:

Um afeto compreende, em primeiro lugar, determinadas inervações motoras ou descargas; em segundo, certas sensações de dois tipos distintos: as percepções das ações motoras ocorridas e as sensações diretas de prazer e desprazer que dão o tom, como se diz, ao afeto. Não acredito, porém, que o com essa enumeração cheguemos à essência do afeto. Em alguns afetos, acreditamos enxergar mais fundo e reconhecer que o núcleo que sustenta o conjunto é a repetição de determinada vivência cheia de significado. Ela poderia ser apenas alguma impressão bastante precoce e de natureza muito geral, que deve ser situada não na pré-história do indivíduo, mas na da espécie. Para dizê-lo de forma mais compreensível: $O$ estado afetivo seria construído como um ataque histérico, seria, como esse, o precipitado de uma reminiscência. $O$ ataque histérico é comparável, portanto, a um afeto individual recémformado, e o afeto normal, à expressão de uma histeria geral que se tornou herança (FREUD, [1917]2014a, pp. 523-524).

Não tão diferente, Freud demonstra em seu livro Inibições, Sintoma e Angústia ([1926]2014b) que a angústia não seria criada no processo de repressão, e sim surgida através da reminiscência de traços mnêmicos pré-existentes. Além disso, acrescenta-se que determinados estados afetivos ficariam incorporados na mente após alguma situação traumática no período primitivo da espécie humana que, por sua vez, seriam revividos como símbolos mnêmicos quando uma situação carregada de alguma semelhança ocorresse (RITVO, 1992).[20]

Além disso, em sua explicação sobre "o tema da explicação fisiológica do riso, ou seja, da derivação ou interpretação das ações musculares características do riso" (FREUD, [1905]2017, p. 209), tema este também discutido por Darwin, "mas nunca resolvido definitivamente" (FREUD, [1905]2017, p. 209), Freud menciona que:

... a careta consistente em recuar os cantos da boca, que é característica do sorriso, aparece pela primeira vez no bebê quando ele, satisfeito e saciado, adormece e larga o peito. Ela é um autêntico movimento expressivo, já que corresponde à decisão de não receber mais alimento, como que dizendo "foi o suficiente, ou, antes, "mais do que o suficiente". Esse sentido original de saciedade prazerosa pode ter dado ao sorriso, que é o fenômeno fundo do riso, a sua relação posterior com os processos prazerosos de descarga (FREUD, [1905]2017, p. 209). 
Embora o uso em maior proporção do primeiro princípio, o segundo princípio aparece apenas no que Freud refere-se como ideias antitéticas, contudo, não é certo que de fato é uma contribuição de Darwin. Entretanto, o terceiro princípio também aparece com maior nitidez e frequência.

A noção de transbordamento da excitação, também entendida como ação direta do sistema nervoso, considera que a função do cérebro primordialmente é evitar uma quantidade excessiva de excitação cerebral. Em vista disso, são realizados meios de descarga desta excitação; por vez, movimentos são gerados com este intuito, principalmente aqueles que chamamos de involuntários, bem como a redução das sensações de desprazer (DARWIN, [1872]2009; RITVO, 1992). Neste mesmo sentido, Freud percebe como está em jogo as noções de prazer e desprazer e, consequentemente, o papel ativo do aparelho psíquico fundamentado por uma topologia e tramas simbólicas - representações - e o sistema motor, que possibilitam a descarga pulsional. Em outras palavras, promovem a redução das sensações de desprazer (RITVO, 1992).

Referindo-se à histeria, essa quantidade de excitação promove a descarga em expressões não convencionais, pois são direcionadas para outras partes do sistema fisiológico devido ao transbordamento (RITVO, 1992). Além disso, pode-se dizer que esse papel na minimização da excitação direcionou à noção freudiana de que um dos papéis do aparelho psíquico é sempre buscar as vias que foram encontradas outrora para minimizar a sensação de desprazer gerada pela excitação. Logo, em busca das sensações de prazer, o sujeito tende ao retorno do caminho já percorrido, ou melhor dizendo, um retorno a traços mnêmicos de satisfação. Ademais, posteriormente, de maneira completamente latente, as implicações das interlocuções freudianas com a biologia darwiniana, sobretudo em relação com o entendimento dos mecanismos de redução do desprazer, acabariam por contribuir com as noções desenvolvidas acerca do mecanismo de repressão, tão fundamental em todo escopo teórico da teoria psicanalítica de Freud (RITVO, 1992). 


\section{À GUISA DE CONCLUSÃO}

"If I have seen further it is by standing on the shoulders of Giant" [Se eu vi mais longe, foi por estar de pé sobre os ombros de gigantes] disse Isaac Newton no dia 5 de fevereiro de 1676, em uma carta enviada a Robert Hooke (NEWTON e HOOKE, 1676). As afirmações de Newton definem claramente o que é a relação de Freud com Darwin. É evidente que as contribuições de Darwin são muito maiores do que um limitado uso teórico. Para Freud, Darwin foi uma inspiração e, como toda inspiração, os desdobramentos se dão de uma maneira indiscutível, seu empenho em se tornar cientista veio à luz de Darwin.

Felizmente, compreender essa relação se tornou possível, em especial, a partir das contribuições da autora Lucille Ritvo. Aparentemente, a sua principal contribuição para essa discussão foi o fato de conceder a Carl Claus um lugar especial na formação acadêmica de Freud, principalmente no que concerne a seus estudos da biologia evolutiva, em contraposição com a pouca atenção por parte de seus biógrafos. Todavia, Ritvo também forneceu embasamento suficiente para outros parâmetros dos textos de Freud, demonstrando a influência de Darwin desde textos como Estudo sobre a Histeria (1895) a Totem e Tabu (1913) e Moisés e o Monoteísmo (1939), bem como a devoção do psicanalista em relação a Darwin desde sua biblioteca física pessoal a seu próprio alojamento na estante das ditas feridas narcísicas ao lado do evolucionista inglês.

Sendo assim, através de toda explicitação empreendida em todo o texto, pode-se concluir que a importância da autora Lucille Ritvo para compreensão da relação Darwin-Freud e o estatuto filogenético da psicanálise freudiana configura-se como algo sólido e inquestionável.

No entanto, por mais profícua que seja a escolha e o uso das considerações de Ritvo para elucidar sobre a relação entre os dois autores em questão, em hipótese alguma os postulados aqui empregados conseguirão englobar toda a discussão no entorno dessa relação, principalmente por este se limitar ao uso de apenas uma autora como guia principal. Além disso, cabe ressaltar que de nenhuma maneira esse estudo 
conseguiu abarcar todo o escopo de contribuições da autora para a temática. Portanto, configura-se também como um convite à leitura dos artigos e do livro da mesma.

Por fim, esse estudo configura-se como uma contribuição original, em especial devido à sua característica focal e estrita à autora, visto que não possuem estudos publicados na literatura que objetivaram igualmente; não obstante, é digno de menção que, embora o recurso aos estudos da Ritvo seja por ora uma via utilizada por aqueles que visam explicitar acerca dessa temática, poucos são os casos que de fato mencionam ou oferecem os devidos créditos à autora. Sendo assim, a necessidade de reinvindicação desse lugar de certo modo demonstra a conspícua e lamentável permanência em discursos e posicionamentos de desmerecimento com autores do sexo feminino, sobretudo, de modo latente.

\section{REFERÊNCIAS}

ASSOUN, Paul-Laurent. Introdução à epistemologia freudiana. Tradução Hilton Japiassu. Rio de Janeiro: Imago, 1983

BIZZO, Nélio Marco. O que é Darwinismo. São Paulo: Brasiliense, 1987.

BOWLBY, John. Psicanálise e teoria da evolução. 1977. Disponível online em: http://repositorio.ispa.pt/bitstream/10400.12/1934/1/1977_1_63.pdf

BUICAN, Denis. Darwin e o Darwinismo [Darwin et le Darwinisme]. Rio de Janeiro: Jorge Zahar, 1990.

BREUER, Josef \& FREUD, Sigmund. Estudo sobre a histeria. In: FREUD, Sigmund. Obras completas, volume 3. Tradução Laura Barreto; Revisão da tradução Paulo César de Souza. São Paulo: Companhia das letras, 2016. (Trabalho original publicado em 1895).

DARWIN, Charles. The Origin of species by means of natural selection, or the preservation of favoured races in the struggle for life. $6^{\mathrm{a}}$ Edition. London: John 
Murray, 1876. (1 ${ }^{a}$ Edição publicada em 1859). Disponível online em: http://darwinonline.org.uk/converted/pdf/1876_Origin_F401.pdf

DARWIN, Charles. The Variation of Animals and Plants under Domestication. London: John Murray, 1868.

DARWIN, Charles. Insectivorous Plants. London: John Murray, 1875

DARWIN, Charles. Autobiografia 1809-1882. São Paulo: Contraponto, 2000. (Trabalho original publicado em 1887)

DARWIN, Charles. A expressão das emoções no homem e nos animais. São Paulo: Companhia das Letras, 2009. (Trabalho original publicado em 1872)

DARWIN, Charles. A origem do homem e a seleção sexual. 2ª Edição. Belo Horizonte: Garnier, 2019. (Trabalho original publicado em 1871)

DAWKINS, Richard. A grande história da evolução: na trilha dos nossos ancestrais. Tradução Laura Teixeira Motta. São Paulo: Companhia das Letras, 2009.

FOUCAULT, Michel. As palavras e as coisas: uma arqueologia das ciências humanas. Tradução Salma Tannus Muchail. São Paulo: Martins Fontes, 1999.

FREUD, Sigmund. Sobre a Psicopatologia da Vida Cotidiana. In: FREUD, Sigmund. Edição Standard Brasileira das obras Psicológicas completas de Sigmund Freud, volume VI. Rio de Janeiro: Imago, 2006. (Trabalho original publicado em 1901)

FREUD, Sigmund. Além do princípio do prazer. In: FREUD, Sigmund. Obras completas, volume 15 (pp. 161-240). Tradução Paulo César de Souza. São Paulo: Companhia das letras, 2010. (Trabalho original publicado em 1920)

FREUD, Sigmund. Psicologia das Massas e Análise do Eu. In: FREUD, Sigmund. Obras completas, volume 15 (pp. 13-99). Tradução Paulo César de Souza. São Paulo: Companhia das letras, 2011a. (Trabalho original publicado em 1921) 
FREUD, Sigmund. O Eu e o Id. In: Obras completas, volume 16 (pp. 13-59). Tradução Paulo césar de Souza. São Paulo: Companhia das letras, 2011b. (Trabalho original publicado em 1923)

FREUD, Sigmund. Autobiografia. In: FREUD, Sigmund. Obras completas, volume 16 (pp. 75-167). Tradução Paulo césar de Souza. São Paulo: Companhia das letras, 2011c. (Trabalho original publicado em 1925)

FREUD, Sigmund. Totem e Tabu. In: FREUD, Sigmund. Obras completas, volume 11. Tradução Paulo césar de Souza. São Paulo: Companhia das letras, 2012a. (Trabalho original publicado em 1913 [1912-1913]

FREUD, Sigmund. Contribuição à História do Movimento Psicanalítico. In: FREUD, Sigmund. Obras completas, volume 11 [1912-1914]. Tradução Paulo césar de Souza. São Paulo: Companhia das letras, 2012b. (Trabalho original publicado em 1914]

FREUD, Sigmund. Conferências Introdutórias à Psicanálise. In: FREUD, Sigmund. Obras completas, volume 13 (pp. 325-593). Tradução Sergio Tellaroli. São Paulo: Companhia das letras, 2014a. (Trabalho original publicado em 1917 [1916-1917])

FREUD, Sigmund. Inibição, Sintoma e Angústia. In: FREUD, Sigmund. Obras completas, volume 17 (pp. 13-123). Tradução Paulo césar de Souza. São Paulo: Companhia das letras, 2014b. (Trabalho original publicado em 1926)

FREUD, Sigmund. O chiste e sua relação com o inconsciente. In: FREUD, Sigmund. Obras completas, volume 7. Tradução Fernando Costa Mattos e Paulo César de Souza. São Paulo: Companhia das letras, 2017. (Trabalho original publicado em 1905)

FREUD, Sigmund. Moises e o Monoteísmo: Três ensaios. In: FREUD, Sigmund. Obras completas, volume 19 (pp. 13-181). Tradução Paulo césar de Souza. São Paulo: Companhia das letras, 2018. (Trabalho original publicado em 1939 [19341938]). 
FREUD, Sigmund. Posfácio a "A questão da análise leiga". In: FREUD, Sigmund. Obras incompletas - Fundamentos da clínica psicanalítica, volume 6. Tradução Claudia Dombusch. Belo Horizonte: Autêntica, 2019. (Trabalho original publicado em 1927)

GAY, Peter. Freud: Uma vida para o nosso tempo. 2ª Edição. São Paulo: Companhia das letras, 2012.

GOODWIN, James. História da psicologia moderna. Tradução Marta Rosas. São Paulo: Cultrix, 2005.

JONES, Ernest. The life and Work of Sigmund Freud (volume 3 - The Last Phase - 1919-1939). First Edition. New York: Basic Books, 1953. Disponível online em: https://monoskop.org/images/5/54/Jones_Ernest_The_Life_and_Work_of_Sigmund_ Freud_3_The_Last_Phase_1919-1939_1957.pdf

LORENZ, Konrad. Prefácio. In: As expressões das emoções no homem e nos animais. São Paulo: Companhia das letras, 2009.

MARTINS, Lilian. C. P. A Teoria da Progressão dos Animais de Lamarck. Rio de Janeiro/São Paulo: Booklink/Fapesp/GHTC-Unicamp, 2007.

MEZAN, Renato. Que tipo de ciência é, afinal, a psicanálise?. Natureza Humana, v. 9, n. 2, p. 319-359, 2007.

NEWTON, Isaac \& HOOKE, Robert. Isaac Newton letter to Robert Hooke. 1675. Disponível online em: https://discover.hsp.org/Record/dc-9792/Description\#tabnav.

RITVO, Lucille. Darwin of the mind. Master's thesis, Yale Medical Historical Library, 1963.

RITVO, Lucille. Darwin as the source of Freud's neo-Lamarckism. Journal of the American Psychoanalytic Association, v. 13, n. 2, p. 499-517, 1965. 
RITVO, Lucille. Carl Claus as Freud's professor of the new Darwinian biology. The International Journal of Psychoanalysis, London, v. 53, n. 2, p. 77-283, 1972.

RITVO, Lucille. The impact of Darwin on Freud. The Psychoanalytic Quarterly, 43(2), p. 177-192, 1974.

RITVO, Lucille. A influência de Darwin sobre Freud: Um conto de duas ciências. Trad: Julio césar castañon Guimarães. Rio de janeiro: Imago, 1992.

ROUDINESCO, Elisabeth. Dicionário de Psicanálise. Rio de Janeiro: Jorge Zahar. 1998.

Disponível online

em: https://monoskop.org/images/c/c9/Roudinesco_Elisabeth_Plon_Michel_Dicionario_d e_psicanalise_1998.pdf

ROSE, Michael Robertson. O Espectro de Darwin: A Teoria da evolução e suas implicações no mundo moderno. Rio de Janeiro: Jorge Zahar, 2000.

SIMANKE, Richard Theisen. A psicanálise freudiana e a dualidade entre ciências naturais e ciências humanas. Scientle studia, São paulo,v. 7, n. 2, p. 221-235, 2009

SULLOWAY, Frank. Freud, biologist of the mind - beyond the psychoanalytic legend. London: Harvard University Press, 1992.

YOUNG, Allan. Remembering the Evolutionary Freud. Science In Context, v. 19, n. 1, p. 175-189, 2006. http://dx.doi.org/10.1017/s0269889705000815.

\section{APÊNDICE - REFERÊNCIAS DE NOTA DE RODAPÉ}

2. O uso da expressão "Espectro de Darwin" aparece primordialmente no livro de Rose (2000), no entanto, foi empregada de uma maneira diferente desse artigo.

3. Em uma linha de raciocínio parecida, Frank Sulloway mencionou Freud como criptobiológo. Não obstante, é digno de menção que, como demonstra Ferreti (2011), Sulloway também foi importante para as pesquisas acerca da relação Darwin-Freud, sobretudo, por este demonstrar a influência de Darwin sobre Freud a partir de "uma 
reflexão sobre os temas abordados em seus trabalhos, como o estudo da emoção, a sexologia, a psicologia infantil e a antropologia, por fim, mostrando que "as ideias do célebre evolucionista inglês encontram intenso eco na obra freudiana." (FERRETI, 2011. p. 110)

4. É valido mencionar e digno de repetição que ao dizermos "exclusivamente" o intuito é referir-se estritamente à explicitação da relação de Darwin e Freud e, portanto, embora pontuais, outras referências também foram utilizadas por motivos de entendimento, sobretudo, acerca de conceitos citados ou para enfatizar determinadas considerações.

5. Ernest Heinrich Haeckel (1834-1919) foi um biólogo e filosofo alemão, também professor de zoologia. O mesmo, também foi o primeiro defensor alemão da evolução orgânica e um dos primeiros defensores de Darwin; Enunciou a lei biogenética, segundo a qual no desenvolvimento do animal individual os estágios da história da evolução da espécie pressuposta se repetem. Em outras palavras, a dita Lei de Haeckel sugere que um organismo, ao se desenvolver a partir de um ovo, passa pelas mesmas mudanças que a espécie ao se desenvolver das formas inferiores da vida animal para as superiores (RITVO, 1992, P. 275)

6. Julius Victor Carus (1823-1903), foi um zoólogo alemão, professor na universidade de Leipzig a partir do ano de 1883. O mesmo, é e foi reconhecido por ter sido tradutor das obras de Darwin após falecimento de Bronn (RITVO, 1992, p. 268)

7. Thomas Henry Huxley (1825-1895), foi um biólogo inglês e presidente da Royal Society (1883-85), foi um destacado defensor da teoria de Darwin na Inglaterra, em especial, no período de maiores embates (Ritvo, 1992, p. 279)

8. É valido pontuar que tais considerações sobre Haeckel foram enviadas a Darwin em uma carta datada no ano de 1865 (ver RITVO, 1992, p. 29)

9. É valido contextualizar que a menção sobre "obscura Alemanha da época" nesta frase, também está direcionada ao conhecimento desenvolvido em Viena. 
10. Um breve demonstrativo dessa questão aparece na seção seguinte deste estudo.

11. Também chamada de força ortogéntica, pressupõe fatores predeterminantes internos que predestinam a evolução progressiva independente de seleção natural ou outros fatores externos (RITVO, 1992, p. 307). Para mais, ver (MARTINS, 2007)

12. Para maior entendimento, ver Ritvo (1992, p. 67).

13. Em uma linha de pensamento darwiniana, portanto, em concordância com Darwin e em oposição a esta tese, sabemos que a "evolução biológica não tem uma linha de descendência privilegiada, nem um fim projetado. A evolução alcançou muitos milhões de fins provisórios [...], e não há nenhuma razão além da vaidade [...] para designar qualquer um mais privilegiado ou mais culminante que o outro (DAWKINS, 2009, p. 21)

14. Cabe salientar - uma vez que o texto é baseado em argumentos biológicos - que a noção de órgão empregada não se refere ao sentido estrito da palavra, principalmente devido ao fato de o aparelho psíquico não ser de fato um órgão.

15. É de extrema importância comentar que mesmo a partir de Ritvo (1962; 1965; 1972; 1974; 1922), a importância do conceito de seleção sexual sobre os estudos de Freud não aparece de maneira explicita, mesmo que tal conceito aparentemente tenha alguma relação com a teoria da horda.

16. A permanência de termos como "renúncia instintual" pode ser pauta para discussão e questionamentos, principalmente devido aos debates acerca das traduções dos termos freudianos. No entanto, sua menção será mantida conforme é empregada nas traduções utilizadas, até porque trata-se de uma citação direta.

17. Cabe pontuar aqui, que o assunto em questão não possui demasiada atenção de Ritvo, logo, não será discutido aqui com maior detalhe, contudo, é de extrema importância salientar que a noção de Naturwissenschaften, tal como Freud conheceu e imaginou, configura-se um tanto diferente de como a conhecemos hoje, como ressalta Mezan (2007). 
18. Embora seja austríaco, portanto, não alemão, a maioria das referências teóricas e estudiosas da época eram derivadas da Alemanha.

19. Anna von Lieben foi uma das pacientes de Sigmund Freud e Josef Breuer cujo caso é relatado em seus Estudos sobre a histeria, sob o nome de Frau Cäcilie M (ROUDINESCO, 1998, p. 476)

20. Ver Ritvo (1992, p. 234) e Freud ([1926]2014b, pp. 13-124)

Enviado: Setembro, 2020.

Aprovado: Setembro, 2020. 